\title{
The Study of the Automatic Manual Truck Transmission Clutch Performance
}

\author{
Aleksandr Blokhin \\ Scientific and Educational Centre "Transport", Nizhny Novgorod State Technical University named after R.Y. Alekseev (NNSTU) \\ Russian Federation
}

\author{
Vasily Mankovsky \\ "KOM" group Nizhny Novgorod \\ Russian Federation
}

\author{
Abram Kropp \\ "Scientists of the south" \\ Gedera, Israel
}

\begin{abstract}
The paper describes the research conducted in the NSTU named after R.E. Alekseev to design and create clutch linkage of the multispeed manual transmissions with automatic control and pneumatic actuator. It represents a general scheme of the transmission and clutch control, design model of the clutch control mechanism, general equations that allow choosing the necessary drive parameters, the experimental data obtained on a specialized stand and the used measuring equipment.
\end{abstract}

Keywords-friction clutch; automatic mechanical transmission; electro-drive; automatic control

\section{INTRODUCTION}

At present, the increasing development on the vehicles gets an automatic transmission control connected with the desire to facilitate and simplify the process of driving. For road cars systems of automatic and semi-automatic (command) transmission and clutch control are being designed. In this context, the purpose of this work is to create experimental models of transmissions with automatic and command control for trucks and buses, providing high dynamic and economic performances and reducing the impact of human factors on the processes of control due to the use of adaptive microprocessor systems.

Specialists of the FEDERAL STATE UNITARY ENTERPRISE CENTRAL SCIENTIFIC RESEARCH AUTOMOBILE AND AUTOMOTIVE ENGINE INSTITUTE, the NSTU named after R.E. Alekseev and the KOM Group of companies developed a family of multispeed (from 8 to 16-speed) transmissions with automatic and command control (Fig. 1), which are described in the works [1-6]. These studies describe design features of transmissions using types and cuts of the basic 16-speed transmission, analyze kinematic and force parameters compared to world analogues, as well as discuss the concept of automatic and command control. Table 1 shows general specifications of the basic 16-speed transmission.

In this paper, in contrast to the above mentioned ones, the emphasis is on the clutch control system for a family of multispeed transmissions, including 8-, 12- and 16-speed modification.

\section{THE STUDY OF THE CLUTCH PERFORMANCE}

The first objective of the study was to develop and manufacture a universal mechanism of the serial clutch control from the leading manufacturers, such as ZF Sachs, whose technical characteristics are shown in Table 2. For this purpose, the design scheme has been developed (Figure 2). It shows that the clutch control mechanism consists of two major parts: a power chamber (Pos.1), and an accelerating mechanism (pos. 2). When voltage is applied to the solenoid valve (Pos. 3) the air from the receiver enters the cavity of the acceleration mechanism piston. As a result, it leads to the opening of the discharge valve through which the pressure of the compressed air is transferred to the power chamber; it causes displacement of the piston rod of the power chamber, of the clutch fork and of the other parts and turns off the clutch.

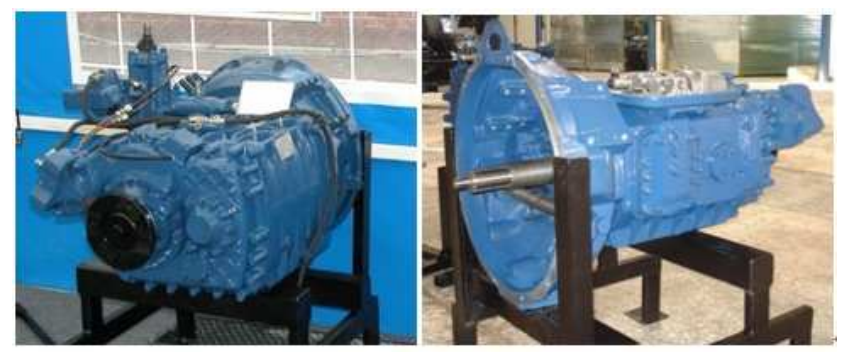

FIGURE I. EXPERIMENTAL SAMPLES OF THE TRANSMISSIONES TM16-2000.

TABLE I . TABLE 1. ERAL CHARACTERISTICS OF THE MULTISTAGE TRANSMISSION.

\begin{tabular}{|l|c|}
\hline Maximum engine power, $\mathbf{k W}$ & 450 \\
\hline Maximum torque, Nm & 2300 \\
\hline Number of gears & 16 \\
\hline The range of gear ratios & 17,53 \\
\hline & $\begin{array}{l}\text { 1. Automatic electropneumatic with } \\
\text { microprocessor units } \\
\text { 2. Command electropneumatic with the } \\
\text { controls }\end{array}$ \\
\hline
\end{tabular}


TABLE II . MAIN CHARACTERISTICS OF THE CLUTCH ZF SACHS MFZ 430.

\begin{tabular}{|l|c|}
\hline \multicolumn{2}{|l|}{ The diameter of the friction facings, $\mathbf{m m :}$} \\
\hline external & 430 \\
\hline internal & 240 \\
\hline \multicolumn{2}{|c|}{ Compression spring: } \\
\hline Type & central, diaphragm \\
\hline The gear ratio of the spring & 4,84 \\
\hline
\end{tabular}

In order to enable the clutch, it is necessary to remove stress from the solenoid valve (pos. 3). In this case, under the action of the return spring mechanisms, the details of the clutch mechanism return to their original position and the pressure in the power chamber reduces to the atmospheric value.

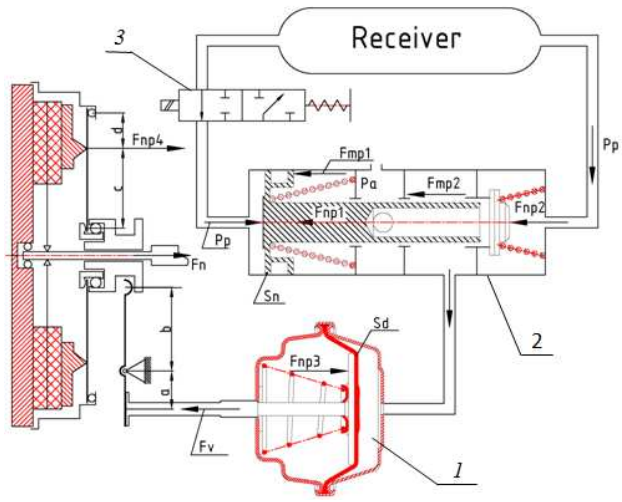

FIGURE II. THE DESIGNED MODEL OF THE CLUTCH CONTROL MECHANISM.

The main parameters of the clutch control mechanism: the cross section of the feeding channels, the diameters of the active elements, the rigidity of the system, the allowed values of the friction components were determined on the basis of the equation:

Where $\mathrm{x}-$ is the rod movement of the considered nod (the power cylinder rod and acceleration mechanism piston).

$$
m \ddot{x}+c \cdot x=a \cdot t-b
$$

In equation (1) coefficient a is connected with a variation of pressure in the system, which is defined by the expressions:

$$
\begin{gathered}
\frac{d p}{d t}=\frac{R T}{V} \mu F \sqrt{\frac{2 g}{R T} p_{p}^{2} \frac{k}{k+1}\left(\frac{2}{k+1}\right)^{\frac{2}{k-1}}} \\
\frac{d p}{d t}=\frac{R T}{V} \mu F p_{p} \sqrt{\frac{2 g k}{R T(k-1)}\left[\left(\frac{p}{p_{p}}\right)^{\frac{2}{k}}-\left(\frac{p}{p_{p}}\right)^{\frac{k+1}{k}}\right]}
\end{gathered}
$$

where $\mathrm{pp}$ - the pressure in the receiver, from which the air outflows; $\mathrm{p}$ - the current pressure in the power cylinder , $\mathrm{H} / \mathrm{m} 2$; $\mathrm{V}$ - the volume of the cylinder into which the air outflows, m3; $\mathrm{T}$ - absolute temperature of the air, ${ }^{\circ} \mathrm{K} ; \mathrm{R}-$ the gas constant,
$\underline{\mathrm{H} \cdot \mathrm{M}}$

$\overline{\mathrm{H} \cdot{ }^{\circ} \mathrm{K}} ; \mathrm{R}=29.27 ; \mathrm{k}$ - adiabatic index for the air $\mathrm{k}=1.41$, $\mathrm{g}-$ gravity acceleration, $\mathrm{m} / \mathrm{s} 2 ; \mu$ - discharge coefficient; $\mathrm{F}-$ the jet section, through which the air outflows $\mathrm{m} 2$.

Expression (2) is used for the air outflow critical zone and (3) is use for the subcritical zone.

Based on the values of the parameters the construction documentation was developed and the details of the clutch control mechanism were manufactured. Figure 3 shows the mechanism installed on the 16-speed transmission.

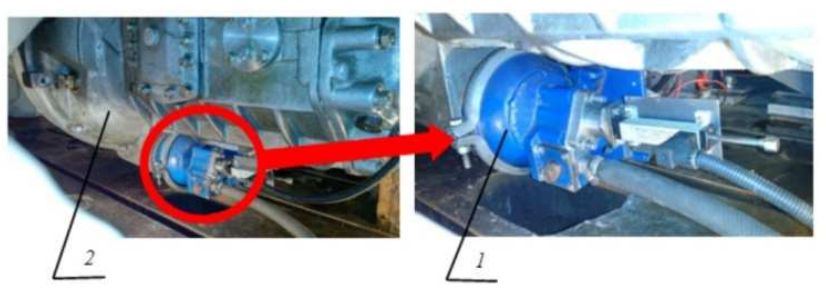

FIGURE III. TYPE OF THE CLUTCH CONTROL MECHANISM INSTALLED ON THE TRANSMISSION.1 - THE DESIGNED CLUTCH CONTROL MECHANISM; 2 - MULTISTAGE TRANSMISSION.

A further objective of the study was to test the operation of the clutch control mechanism, without ensuring gentle start of the vehicle. For this the NSTU named after R. E. Alekseev conducted experimental studies on the specialized stand (Figure 4) for testing of the transmissions with command and automatic control [7, 8]. The stand allows studying the efficiency of the mechanical transmissions units (clutch, divider, the main speed reduction device, splitter, determining the efficiency of the unit, the study of the synchronization process, etc.) and mechatronic control systems for automatic or semi-automatic modes. Algorithms of the clutch control of the studied transmissions were worked out at this stand.
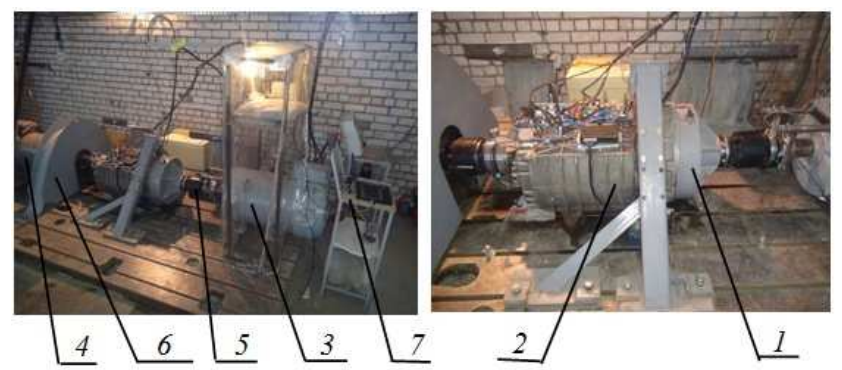

FIGURE IV. TYPE OF THE CLUTCH CONTROL MECHANISM INSTALLED ON THE TRANSMISSION. 1 - THE STUDIED CLUTCH MECHANISM; 2 - MULTISTAGE TRANSMISSION; 3 - DRIVE MOTOR; 4 - LOADING MOTOR; 5 - DRIVELINE; 6 - INERTIAL MASS; 7 REMOTE CONTROL.

Based on the analysis of experimentally obtained data, we made a conclusion on admissibility of the parameters incorporated in the design of the clutch control mechanism.

The third objective of the study was development and testing of the microprocessor control system in co-operation of the transmission and the clutch, including ensuring the smooth clutch turning-on (gentle start off). 
Figure 5 shows the general scheme of the transmission and the clutch control. When choosing the gear for starting on the controller (pos. 5) the control unit (pos. 1) energizes the solenoid valve (pos. 15) of the acceleration mechanism of the clutch which allows to supply the air from the receiver into the cavity of the acceleration mechanism piston and open the pressive valve through which the air pressure is supplied to the power pneumatic chamber (pos. 14) and the clutch turns on, and also the appropriate gear in the divider control mechanisms (pos. 8), the main gear system (pos. 9) and the splitter (pos. 11). When the driver presses the accelerator pedal (pos. 18) the process of starting off begins. Wherein the control unit modulates the signal to the solenoid valve (pos. 15) while maintaining a certain pressure in the pneumatic chamber, which is proportional to the angular position of the accelerator pedal (pos. 18). In accordance with the pressure in the pneumatic chamber the clutch fork occupies a definite position (its position is monitored by a displacement sensor, pos. 19) and the rest cinematically related items, including the clutch pressure plate, thereby defining a gap between the driving and the driven clutch parts and, consequently the friction torque in the clutch. This establishes the proportionality between the position of the accelerator (pos. 18) and the friction torque in the clutch that is necessary for a gentle start.

By changing the frequency and the relative pulse duration on the solenoid valve (pos. 15) of the clutch control mechanism, the clutch turning process control for gentle start was implemented. With setting the relative pulse duration of the solenoid valve we selected the PID-control that is a function of the difference between the theoretical and the actual state of the given displacement sensor (pos. 19).

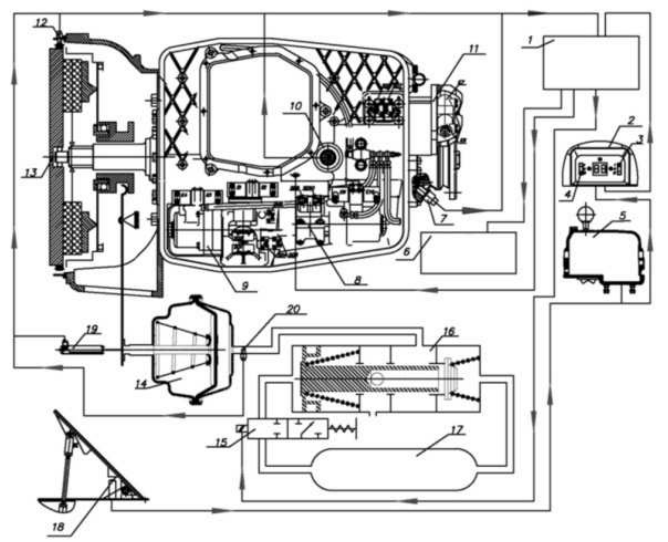

FIGURE V. THE GENERAL SCHEME OF THE TRANSMISSION AND CLUTCH CONTROL. 1 - TRANSMISSION CONTROL UNIT; 2 DISPLAY UNIT; 3 - AUTOMATIC CONTROL FOR VARIOUS CONDITIONS; 4 - ADJUSTMENT TO THE MAXIMUM RATE OF

PRESSURE; 5 - CONTROLLER; 6 - FUEL CONTROL UNIT; 7 - OUTPUT

SHAFT SPEED SENSOR; - DIVIDER CONTROL MECHANISM; 9 -

MAIN GEAR CONTROL MECHANISM; 10 - INTERMEDIATE SHAFT SPEED SENSOR; 11 - SPLITTER CONTROL MECHANISM; 12 -

ENGINE SPEED SENSOR; 13 - CLUTCH; 14 - PNEUMATIC CHAMBER;

15 - ELECTRO-PNEUMATIC CLUTCH CONTROL VALVE; 16 ACCELERATING PNEUMOVALVE; 17 - RECEIVER; 18 -

ACCELERATOR PEDAL; 19 - CLUTCH PLUG MOTION SENSOR; 20 PRESSURE SENSOR IN THE PNEUMATIC CHAMBER.
Figure 6 shows the fragments of oscillograms showing changes in the main adjustable clutch parameters: 1 - clutch plug rod movement; 2 - pressure in accelerating mechanism; 3 - pressure in a clutch control power chamber; 4 - the angular velocity of rotation of the motor shaft (rpm.); 5 - torque on the motor shaft $(\mathrm{Hm})$. Clutch plug rod movement (line 1) plotted on the supporting vertical axis and other parameters - by main.

As a result of studies on the test stand we found that at initial pressures in the receiver of $850 \mathrm{kPa}$, and at the angular velocity of the motor shaft $650 \mathrm{rpm}$, time of starting off the vehicle (gross weight of $20 \mathrm{t}$.) for second gear was $1.8 \mathrm{~s}$. (Figure 6).

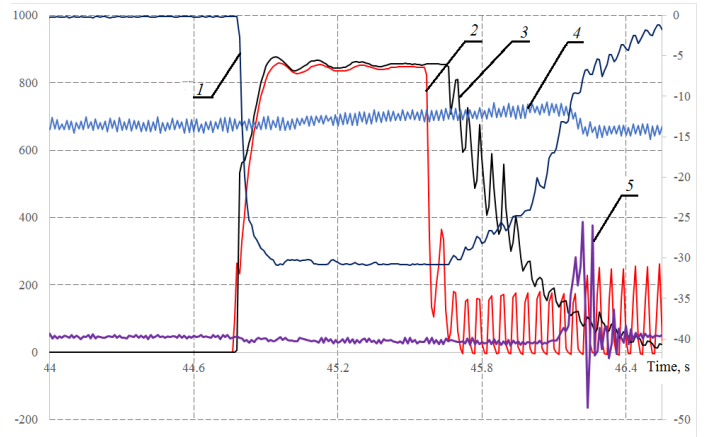

FIGURE VI. THE NATURE OF THE PARAMETER CHANGES IN THE PROCESS OF STARTING OFF WITH THE SECOND GEAR.

\section{CONCLUSION}

1) We developed functional diagram and the mathematical model of the original control mechanism of the dry friction clutch of the vehicles.

2) We developed documentation on the bases of which the original control mechanism of the dry friction clutch of the vehicles was produce.

3) We developed a concept of control and an algorithm of control of the transmission and the clutch that allow gentle starting of the vehicle in various road conditions.

4) The experimental study on the stand confirmed the efficiency of construction of the clutch control mechanism and regulation of the friction torque in the clutch.

\section{ACKNOWLEDGEMENT}

This work was carried out at the NSTU named after R.E. Alekseev, with financial support from the government in the face of the Russian Ministry of Education under the Federal Program "Research and development on priority directions of the scientific-technological complex of Russia for 2014-2020", the unique identifier of the project: RFMEFI57414X0040.

\section{REFERENCES}

[1] Nedyalkov, A.P., Blokhin, A. N., Application of advanced technical solutions when creating a mechanical transmission with automatic control. Science and Education: electronic science and technology publication, 2, 2011, URL http://technomag.edu.ru/doc/165381.html

2] Blokhin, A. N., Innovative transmissiones "KOM-NAMI" with mechanical and automatic control. Science and Education: electronic 
science and technology publication, 9, 2011, URL http://technomag.edu.ru/doc/214551.html

[3] Nedyalkov, A.P., Aleksandrov, E.B., Blokhin, A.N., Analytical study of options for kinematic patterns of multispeed planetary transmission demultiplicators and the choice of optimal parameters of planetary mechanism. Bulletin of the Izhevsk State Technical University, 2 (50), pp. 39-43, 2011.

[4] Nedyalkov, A.P., Trikoz, A.A., Blokhin, A.N., The method to calculate parameters of an inertial cam-free synchronizer with a ring spring element. "Journal of AAE" Journal of the Association of Automotive Engineers, 2 (67), pp. 22-25, 2011.

[5] Nedyalkov, A.P., Blokhin, A.N, Tumreev, V.Yu., Standard series of promising unified multi-synchronized transmission with automatic control. Topical issues of Mechanical Engineering. Collection of scientific papers, Issue 1: Belarus, pp. 216-221, 2012.

[6] Blokhin, A. N., Tumasov, A.V, Nedyalkov, A.P., Mankovsky, V.V., Perspective dimension-types range of mechanical multiple-speed transmission with automatic control system. Proc. of 2012 Int. Conf. on Advanced Vehicle Technologies and Integration (VTI 2012): China, pp. 480-484, 2012.

[7] Blokhin, A.N, Nedyalkov, A.P, Kropp, A.E., The results of stand tests of sixteen speed transmission with automatic control. Science and Education: electronic science and technology publication, 12, 2013, URL http://technomag.edu.ru/doc/671097.html

[8] Blokhin, A.N, Nedyalkov, A. P., Tumasov, A.V., Noskov, A. M., The results of computational and experimental studies of the efficiency of the multistage mechanical transmission with automatic control. Topical issues of Mechanical Engineering. Collection of scientific papers: Belarus, pp. 171-178, 2013. 